\title{
Incidence and root causes of delays in emergency orthopaedic procedures: a single-centre experience of 36,017 consecutive cases over seven years
}

\author{
Ulla Caesar ${ }^{1,3^{*}}$, Jon Karlsson ${ }^{1,3}$ and Elisabeth Hansson ${ }^{2,3}$
}

\footnotetext{
* Correspondence: ulla.caesar@gu.se 'Sahlgrenska Academy, Institute of Clinical Sciences, Department of Orthopaedics, University of Gothenburg Sweden, Gothenburg, Sweden

${ }^{3}$ Department of Orthopaedics, Sahlgrenska University Hospital, Gothenburg, Sweden Full list of author information is available at the end of the article
}

\begin{abstract}
Background: Emergency surgery is unplanned by definition and patients are scheduled for surgery with minimal preparation. Some patients who have sustained emergency orthopaedic trauma or other conditions must be operated on immediately or within a few hours, while others can wait until the hospital's resources permit and/or the patients' health status has been optimised as needed. This may affect the prioritisation procedures for both emergency and elective surgery and might result in waiting lists, not only for planned procedures but also for emergencies.
\end{abstract}

Method: The main purpose of this retrospective, observational, single-centre study was to evaluate and describe for the number and reasons of delays, as well as waiting times in emergency orthopaedic surgery using data derived from the hospital's records and registers. All the emergency patients scheduled for emergency surgery whose procedures were rescheduled and delayed between 1 January 2007 and 31 December 2013 were studied.

Result: We found that 24\% (8474) of the 36,017 patients scheduled for emergency surgeries were delayed and rescheduled at least once, some several times. Eighty per cent of these delays were due to organisational causes. Twenty-one per cent of all the delayed patients had surgery within $24 \mathrm{~h}$, whilst $41 \%$ waited for more than $24 \mathrm{~h}$, up to 3 days.

Conclusion: A large number of the clinic's emergency orthopaedic procedures were rescheduled and delayed and the majority of the delays were related to organisational reasons. The results can be interpreted in two ways; first, organisational reasons are avoidable and the potential for improvement is great and, secondly and most importantly, the delays might negatively affect patient outcomes.

Keywords: Appointments and schedules, Operating rooms/organisation and administration, Waiting lists, Cancellation, Orthopaedic surgery, Emergency delays, Perioperative nursing

\section{Background}

High availability and good quality are regarded as important goals in the Swedish health-care system ( $80 \%$ publicly funded) [1], which aims to provide care on equal terms to all citizens [2]. Delivering care equally and efficiently with high quality is a challenge. One of the areas affected by these challenges is surgery. Emergency surgery is unplanned by definition and patients are scheduled with minimal forward planning.

(c) The Author(s). 2018 Open Access This article is distributed under the terms of the Creative Commons Attribution 4.0 International License (http://creativecommons.org/licenses/by/4.0/), which permits unrestricted use, distribution, and reproduction in any medium, provided you give appropriate credit to the original author(s) and the source, provide a link to the Creative Commons license, and indicate if changes were made. The Creative Commons Public Domain Dedication waiver (http://creativecommons.org/ publicdomain/zero/1.0/) applies to the data made available in this article, unless otherwise stated. 
As a result, they often have to be fitted into a surgery schedule as competition to the electives, when operating room (OR) space is limited. They may otherwise be included as a more highly prioritised emergency disruption to the elective OR list [3-11]. When operations are rescheduled and the waiting time is prolonged, a deterioration in the patients' health may result in unnecessary suffering [12-16], which may in turn cause postponed or poorer recovery and possibly inferior outcomes [17, 18]. Moreover, studies of cancellations of and delays in surgical procedures reveal the inefficient use of hospital resources, as well as a loss of hospital revenues [19-23].

Despite improvements in technical and hospital resources over the last few decades, surgical delays still occur every day in orthopaedic departments [24-26]. These delays could be explained by the high demands related to emergency orthopaedic admissions covering a wide spectrum of injuries that often require surgical management [27]. True orthopaedic emergencies that require immediate surgery are conditions such as acute compartment syndromes and fractures or dislocations associated with vascular injury. Some of the other emergencies can wait without harm, but they have to be managed as soon as the patient's status has been optimised and when the hospital's resources permit [27]. Taken together, emergencies must be considered in terms of the seriousness of the injury, the patient's health status and access to the OR. Moreover, planned surgeries wait for months to be performed. All this requires the prioritisation of the included patients and will in itself create waiting lists for both emergency and elective surgery. In addition, some emergencies enter the OR as competitors when elective surgeries have to be rescheduled [24].

Even though a common reason for cancelling surgery is a prioritised emergency, a growing body of research has focused on delays to and cancellations in elective surgical procedures [3-10, 24, 28]. Moreover, studies have shown a decrease in delayed surgery, when the causes of the delays have been identified [29, 30]. Irrespective of the reason for delays to emergency surgeries, they lead to concerns for the patients and major organisational problems for the clinics. Problems such as extended waiting lists and an overbooked OR, a shortage of hospital beds and cancellations of either elective or emergency surgery at the end of the day are commonly mentioned. Magnusson et al. [31] claimed that a delay might contribute to unnecessary distress and might also lead to a loss of confidence in the hospital. It has also been revealed that feelings of insecurity might lead to increased pain which can in turn lead to a prolonged hospital stay $[13,15,32]$. The main purpose of the current study was to evaluate and describe the number of and reasons for delays, as well waiting time in emergency orthopaedic procedures, at a clinic routinely performing both acute and elective orthopaedic surgery.

\section{Method}

The study was a descriptive single-centre study with the retrospective inclusion of prospective, observational data derived from the hospital's records and registers. The study population comprised all the patients scheduled for emergency orthopaedic surgery, from 1 January 2007 to 31 December 2013 at a university hospital with an annual production of approximately 9500 procedures comprising 46\% planned and 54\% acute surgical procedures. The orthopaedic clinic is organised into specialised teams focusing on trauma, joint replacement, arthroscopic, foot \& ankle, tumour, paediatric orthopaedic and spine surgery. 
The included cases were patients scheduled for emergency procedures who were then delayed. The collected data included age, gender, diagnosis, reason for delay, time of delay and length of time until surgery was performed. The age of the patients ranged between three and 107 years and 54\% of patients were women. During the study period, a total of 36,017 patients were on the surgical emergency waiting list.

The patients entered the hospital from the emergency room (ER), the non-urgent surgery-consulting centre, or from a referral by a physician outside the hospital. All the patients underwent a medical examination and, in several cases, an imaging examination (radiographs, ultrasonography or magnetic resonance), before a decision to perform emergency surgery was made.

At the clinic, three emergency waiting lists ran in parallel each weekday, with three dedicated ORs on weekdays and two at weekends. One OR was specified for hip fracture patients and two for general orthopaedic trauma and "home pathway" patients. We identified patients from all these lists. The "home pathway" patients required surgery but could not be scheduled within $24 \mathrm{~h}$ after admission. These patients could be placed in plaster of Paris, a bandage or a sling before they were discharged to their homes to wait for surgery.

The OR schedule was based on priorities and decisions made by the surgeons and on the hospital's working method, which are as follows.

1. A hip fracture is planned to undergo surgery within $24 \mathrm{~h}$.

2. The emergency in-hospital patients waiting on the ward are planned to undergo surgery within $24 \mathrm{~h}$.

3. "Home pathway" surgery

After the decision, a notification was sent to a co-ordinator who booked the appointment for the surgical procedure. This meant that patient data were entered into the planning system and a file with a patient ID was opened in the electronic planning system (Operätt). In this system, co-ordinators, surgeons and nurses registered data.

To confirm the daily structure and order of priority on the three emergency waiting lists, a regular morning meeting was held at the OR Department. There and then, a senior surgeon prioritised the daily schedule for all the surgery procedures. In a few cases, the senior surgeon did not find any indication for surgery and the procedure was cancelled. After the prioritisation was complete, the co-ordinator contacted the wards to confirm the patients waiting for surgery in hospital. Moreover, phone calls were made to those waiting at home, to inform them of either a delay or a definite time for surgery.

The IT tool, Qlick View (QV), was used as a database and made it possible to identify, calculate and present quality measurements of all activities associated with the emergency surgery waiting list. Qlick View also enabled the identification of all cancellations made in the planning system. The planning system was updated every day and validated every month.

Delays and cancellations were entered into the planning system under one of 47 possible codes and they were merged into three categories; organisational, medical and patient-related reasons. The organisational reasons were due to:

- An emergency case with higher priority 
- The unexpected prolongation of on-going surgery

- Incomplete pre-operative preparations and need for further patient evaluation

- Changed or missing indications for surgery

- Shortage of hospital beds on the wards or at the Intensive care unit (ICU)

- Shortage of staff in the OR, ICU, ward and/or surgeons and anaesthesiologists

Moreover, some of the organisational reasons included the patient being referred to another hospital or another surgical team. The medical reasons included disorders that made the patient inappropriate at the planned time point or totally inoperable, or else that the patient had an on-going infection. The patient-related category was due to the patients' personal wishes to have surgery performed on a later occasion, the patients not showing up at the appointed time or the patients dying or refusing surgery.

The data were managed using IBM SPSS Statistics (Version 21). Descriptive data were presented in absolute and relative numbers, median and range values. Graphics were illustrated using Microsoft Excel (Version 2013).

\section{Result}

Of all 36,017 patients who were scheduled for emergency surgery, $(6604 / 36,017) 18 \%$ had their procedure cancelled once, $4 \%(1490 / 36,017)$ twice, $1 \%(289 / 36,017)$ three times, $<1 \%(58 / 36,017)$ four times and $<1 \%(33 / 36,017)$ more than four times. This adds up to a total number of 10,873 delays for the 8474 actual patients. The produced surgeries totalled 33,925 and 2090 cases on the waiting list did not undergo surgery at the current clinic. The proportions of delays and delayed patients did not change across the 7 years that were studied (Fig. 1).

The two most frequent reasons within the organisational group were that another emergency surgery was given higher priority and the unexpected prolongation of ongoing surgery. Missing OR equipment was the least frequent reason. The organisational reasons amounted to $81 \%(6865 / 8474)$ and, among them, $71 \%$ (4875/6865) were caused by a higher priority emergency case (Fig. 2). Together, the medical and the patientrelated causes had fewer delays than the organisational causes. Sixteen per cent (1393/

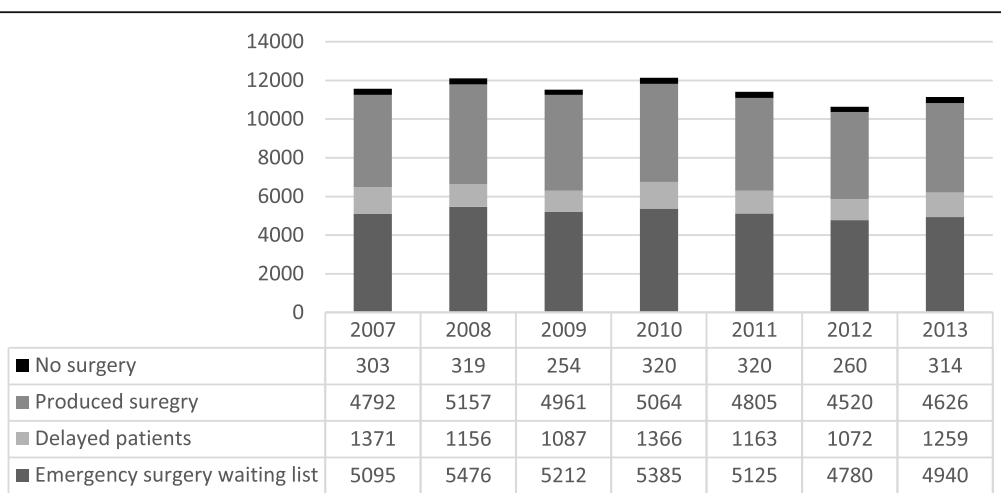

Fig. 1 Produced and delayed emergency surgery 2007-2013. Emergency surgery waiting list; every new patient is entered into an electronic surgical planning system as a file with a unique patient ID. The patient remains in the planning system until the operation is completed, transferred to another care-giver or the patient did not require surgery. Produced surgery; all the patients who underwent surgery at the current clinic. Delayed patients; all the patients that were delayed. No surgery; surgery on the waiting list that did not undergo surgery at the current clinic 


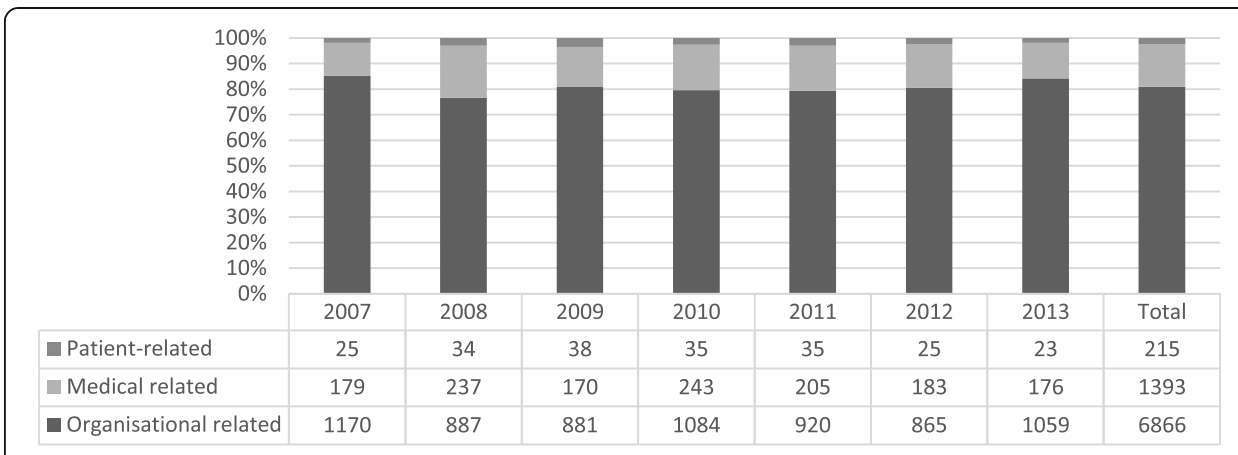

Fig. 2 Reasons for all delayed patients' emergency surgery 2007-2013

$8474)$ of the delays were due to medical reasons and 3\% (215/8474) were due to patient-related reasons (Fig. 2). The reasons for cancellation of emergency surgery were proportionally the same also when cancellations occurred several times.

Of all the delayed emergencies, $21 \%(1035+721 / 8474)$ underwent surgery within $24 \mathrm{~h}$. The highest number, $41 \%$ (3438/ 8474) waited for more than $24 \mathrm{~h}$ and up to 3 days, while $17 \%(1458 / 8474)$ waited from 3 days to 1 week or even more than 1 week (Fig. 3). The group that waited for more than $24 \mathrm{~h}$ up to 3 days decreased during the 7 years that were studied, while those who waited more than 1 week increased. Fifteen per cent (1237/8474) of all delays had no registered waiting time (Table 1).

\section{Discussion}

The most important finding in the present study was the high frequency of rescheduled emergency orthopaedic surgery. Of all the patients scheduled for emergency surgery, $24 \%(8474 / 36,017)$ had their surgical procedure delayed at least once and some several times. Another important finding was that the proportions of delays did not change but were instead fairly constant, over the 7 years that were studied. In Sweden, the large university hospitals tend to have the longest waiting times for planned orthopaedic procedures [33]. Schuster et al. [34] have observed a similar situation in terms of waiting times at German university hospitals. It is important to acknowledge that university hospitals commonly deal with an increased volume of moderate to complex care patients transferred from smaller hospital. Consequently, the number of emergency

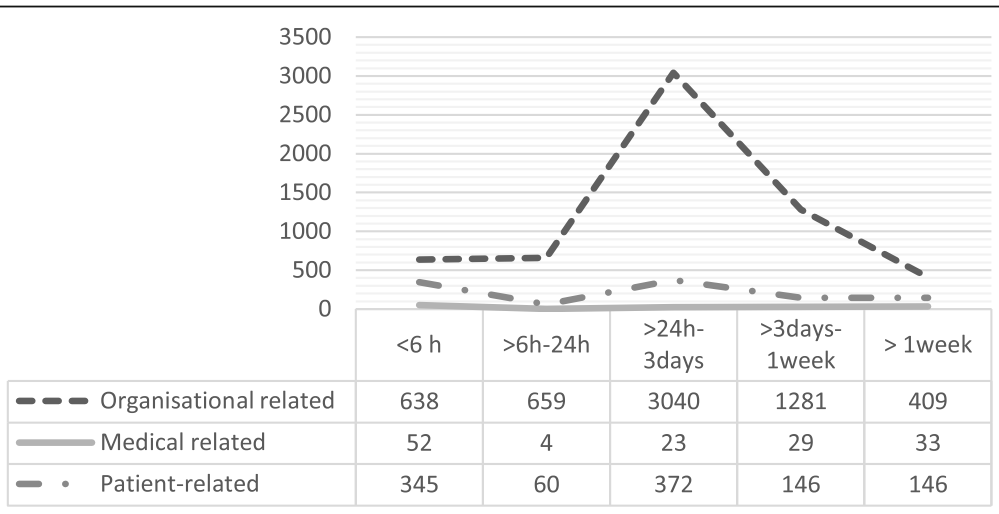

Fig. 3 Waiting time for surgery for all delayed emergency patients by reasons 2007-2013 
Table 1 Waiting time to surgery for all delayed emergency patients 2007-2013

\begin{tabular}{llllllll}
\hline YEAR & $<6 \mathrm{~h}$ & $>6 \mathrm{~h}-24 \mathrm{~h}$ & $>24 \mathrm{~h}-3$ days & $>3$ days-1 week & $>1$ week & missing & Total \\
\hline 2007 & 154 & 100 & 699 & 191 & 51 & 1195 \\
2008 & 160 & 99 & 500 & 167 & 49 & 975 \\
2009 & 121 & 89 & 478 & 176 & 65 & 929 \\
2010 & 159 & 104 & 524 & 292 & 103 & 1182 \\
2011 & 159 & 111 & 428 & 191 & 85 & 974 \\
2012 & 138 & 120 & 387 & 192 & 85 & 922 \\
2013 & 144 & 98 & 422 & 249 & 147 & & 1060 \\
Missing & & & & & & 1237 & 1237 \\
Total & 1035 & 721 & 3438 & 1458 & 585 & 1237 & 8474 \\
\hline
\end{tabular}

patients increases and the situation with overbooked ORs becomes more complex, consistent with extended waiting lists and increasing waiting times.

The present study revealed a variety of reasons for the delays. When grouping, almost $80 \%$ were due to organisational reasons. The large number of delays in this group came from emergencies having an even higher priority. Several studies [10, 35, 36] have reported that emergencies are often the reason for cancellations of elective procedures. Moreover, the review by Cardoon et al. [24] observed that most of the research on the planning and scheduling of surgery focused on elective patients, while major organisational shortages were caused by the arrival of emergency patients. Moreover, Cosgrove et al. [29] and Leppaniemi and Jousela [30] have described methods for prioritising surgery, based on clinical outcomes and existing clinical guidelines. These findings demonstrate that hospitals will be better prepared to avoid delays when the reasons for delays have been clarified.

The second most frequent delay in the present study was related to medical reasons and accounted for $17 \%$ of all the delays. Studies $[37,38]$ have shown that medical reasons are not the most common cause of emergency-related delays. The medical delays are often due to respiratory and/or vascular complications. These and many of the other medically related reasons are unforeseeable and unavoidable and hospitals have few opportunities to influence these types of delay. Some of the delays might be helped by improving the organisation of the preoperative emergency assessment. Several studies have shown fewer delays, with a reduction of $1-8 \%$, when preoperative routines for consulting and assessment have been improved [39].

One finding in the present study was that almost $70 \%$ of the delayed emergencies waited for more than $24 \mathrm{~h}$ up to 1 week before surgery. The acute emergencies which waited less than 6 hours (14\%) might be regarded as not constituting a delay. It appears realistic to wait 6 hours, but the organisation of the OR scheduling is still disrupted, when patients are rescheduled. Emergency care in Sweden is not tied to the health-care guarantee. The prioritisation is determined by the urgency of the medical needs. Patients who have become acutely ill or injured will receive treatment as quickly as possible. However, the National Board of Health and Welfare [40] stepped up the goal in connection with hip-fracture care, stating that surgery should take place on the day of admission or within $24 \mathrm{~h}$ after admission to hospital. Taken as a whole, this results in the hospital's part of prioritisation becoming problematic and recommendations for cut-off times may have both positive and negative effects on all the orthopaedic waiting lists and delays [41]. 
Another finding in the current study was that almost 6\% (2090/36,017) of the patients on the waiting lists did not undergo surgery at the current clinic. Some of these patients could be explained by differences between the first prioritisation of surgery and the later prioritisation, made by the senior surgeon, who did not find any indication for surgery and the procedure was therefore cancelled. Moreover, the patients might not accept the long waiting time and accordingly search for care at another hospital.

When patients reschedule and cancel their surgery, it disrupts the operation planning procedure, especially when this is done at short notice. The present study revealed a low rate $(2 \%)$ of patient-related reasons for delays in emergency surgery. It appears reasonable to suppose that patients do not reschedule acute surgery. On the other hand, almost $40 \%$ of the present clinic's elective cancellations [28] were due to patient-related causes. Several other studies have also observed large numbers of patient-related reasons for cancelling elective surgery [42] and the rescheduling of surgery often leads to unutilised ORs [43].

To respond to the demand from all orthopaedic procedures and the disruptions among elective and emergency cases, the clinic organised the emergency cases into one OR dedicated to hip fractures and two other ORs for both the acute in-patients and the "home-care pathway" patients. The elective surgery was only performed on weekdays and had its own schedule and dedicated OR. Several studies have [44-47] reported that separating emergency from elective surgery reduces delays and cancellations. This was also the case in the present study, but it was not true in terms of the cancellations of emergency procedures; $71 \%$ (4875/6865) of the organisational delays were caused by an even more highly prioritised emergency case. We also found that approximately $80 \%$ of the present clinic's delayed emergency procedures had organisational causes. In a previous study, Caesar et al. [28] revealed that $9 \%$ of the same clinic's elective surgeries were cancelled due to organisational shortages. Taken together, these results illustrate that emergencies are more frequently delayed by an ineffectual organisation rather than planned surgery, which indicates that emergencies are more often delayed by other more highly prioritised emergencies than electives.

Another way to avoid over-booked ORs, as well as the shortage of ward space, was the clinic's organisation using a "home pathway", including patients waiting at home. The "home pathway" is a new concept within orthopaedics. The limited available literature $[48,49]$ indicates that home care is safe if the instructions to select patients, patient information, and contact with the hospital are appropriate and clearly clarified. The results of the current study demonstrated that the group that waited for more than $24 \mathrm{~h}$ up to 3 days decreased during the 7 years that were studied, while those who waited more than a week increased. This might indicate a value of the "home pathway", as more patients waited at home and did not compete with other surgery, thereby allowing the present clinic to schedule surgery in the short term. In addition, this might have ensured the streamlining of the emergency waiting list and may be a more realistic approach to booking surgery and, in the longer term, lead to fewer delays and cancellations.

Surgical complications increase, the longer the waiting time to surgery [50]. Delays longer than $24 \mathrm{~h}$ have proved to be an important risk factor for wound infection in hip fractures. Moreover, older age in patients with hip fractures was a significant risk factor 
for mortality, upper urinary tract infections and pneumonia [51]. Likewise, if ankle fractures were delayed more than $48 \mathrm{~h}$, the length of stay in hospital and the cost increased significantly. Ankle fractures in individuals over 70 years of age have been shown a high rate of complications, such as infection and delayed wound healing, and they therefore need to be prioritised [52]. Pettersson et al. [41] demonstrated that $20 \%$ of hip-fracture patients suffered a serious adverse event during their hospital stay and the risk of complications occurring increased linearly over time. Reducing delays in the preoperative care process of orthopaedic emergency surgery appears to reduce the risk of complications and serious adverse events in patients. One way might be to implement procedures for prioritisation based on evidence from research and clinics.

The "home pathway", at least at the current clinic, is an unexplored pathway and a fairly new phenomenon in emergency care. The organisational outcomes and waiting times, as well as patients' experiences of waiting at home for emergency orthopaedic surgery, are areas for further research.

\section{Limitations}

There are several limitations to this study. First, as the data come from a single hospital, the results are difficult to generalise to other orthopaedic clinics, with different functional characteristics, such as size, services provided and case mix. Another limitation could be that different staff categories entered the data into the surgical planning system, Operätt. This could lead to the inconsistent grouping of the reasons for cancellations. Since there is both a continuous inflow and outflow from the current clinic's waiting lists, the numbers given may vary. This makes it difficult to provide the precise numbers from one moment to another.

\section{Conclusion}

Hospitals and clinics need to deal with the root causes of inefficiency and shortages in many ways. Clarifying the reasons for delays to orthopaedic procedures is the first and probably the most important step when it comes to dealing with the root causes and shortages at the present hospital, in order to decrease both elective and acute surgery delays and cancellations.

The large number of organisational delays in the present study is a major quality problem affecting the individual patient and the actual health-care organisation, as well as prolonging sick leave. While many of the organisational reasons are avoidable, some of them are still caused by factors that are outside the responsibility of the individual clinic or even the hospital. Many of the delays, such as the medical reasons, appear to be impossible to reduce or eliminate, but some might nonetheless be helped by improving the organisation of preoperative emergency assessments. 


\section{Authors' contributions}

UC, EHO and JK were responsible for the study conception and design and the drafting of the manuscript, UC performed the data collection and UC and EHO performed the data analysis. UC and EHO provided the appropriate ethical information to the ethics committee. JK and EHO made critical revisions to the paper. EHO supervised the study. All the authors read and approved the final manuscript.

\section{Ethics approval and consent to participate}

The Regional Ethics Committee Review Board situated at the University of Gothenburg approved the study, Dnr: $531-12$.

\section{Competing interests}

The authors declare that they have no competing interests.

\section{Publisher's Note}

Springer Nature remains neutral with regard to jurisdictional claims in published maps and institutional affiliations.

\section{Author details}

${ }^{1}$ Sahlgrenska Academy, Institute of Clinical Sciences, Department of Orthopaedics, University of Gothenburg Sweden, Gothenburg, Sweden. ${ }^{2}$ Sahlgrenska Academy, Institute of Health and Care Sciences, University of Gothenburg Sweden, Gothenburg, Sweden. ${ }^{3}$ Department of Orthopaedics, Sahlgrenska University Hospital, Gothenburg, Sweden.

Received: 7 December 2017 Accepted: 4 January 2018

\section{Published online: 11 January 2018}

\section{References}

1. The burden of musculoskeletal conditions at the start of the new millenium WHO Report 2003 [http://www.who. int/publications/en/].

2. Swedish healt care act, SFS Hälso- och sjukvårdslag. 1982:763 [https://www.riksdagen.se/sv/dokument-lagar/ dokument/svensk-forfattningssamling/halso-och-sjukvardslag-1982763_sfs-1982-763].

3. Lacqua MJ, Evans JT. Cancelled elective surgery: an evaluation. Am Surg. 1994;60:809-11.

4. Epstein RH, Dexter F. Rescheduling of previously cancelled surgical cases does not increase variability in operating room workload when cases are scheduled based on maximizing efficiency of use of operating room time. Anesth Analg. 2013;117:995-1002.

5. Thomson PJ. Cancelled operations. A current problem in oral and maxillofacial surgery. Br Dent J. 1991;171:244-5.

6. Lau HK, Chen TH, Liou CM, Chou MC, Hung WT. Retrospective analysis of surgery postponed or cancelled in the operating room. J Clin Anesth. 2010;22:237-40.

7. González-Arévalo A, Gómez-Arnau JI, DelaCruz FJ, Marzal JM, Ramírez S, Corral EM, García-del-Valle S. Causes for cancellation of elective surgical procedures in a Spanish general hospital. Anaesthesia. 2009;64:487-93.

8. Yoon SZ, Chang SH. Analysing day-of-surgery cancellation rates - reply. Anaesth Intensive Care. 2009;37:858-9.

9. Ehrenfeld JM, Dexter F, Rothman BS, Johnson AM, Epstein RH. Case cancellation rates measured by surgical service differ whether based on the number of cases or the number of minutes cancelled. Anesth Analg. 2013; 117:711-6.

10. Hovlid E, Bukve O. A qualitative study of contextual factors' impact on measures to reduce surgery cancellations. BMC Health Serv Res. 2014;14:215.

11. Hovlid E, Bukve $\mathrm{O}$, Haug $\mathrm{K}$, Aslaksen AB, von Plessen C. A new pathway for elective surgery to reduce cancellation rates. BMC Health Serv Res. 2012;12:154.

12. Ivarsson B, Kimblad PO, Sjoberg T, Larsson S. Patient reactions to cancelled or postponed heart operations. J Nurs Manag. 2002;10:75-81.

13. Ivarsson B, Larsson S, Sjoberg T. Postponed or cancelled heart operations from the patient's perspective. J Nurs Manag. 2004;12:28-36.

14. Fitzsimons D, Parahoo K, Richardson SG, Stringer M. Patient anxiety while on a waiting list for coronary artery bypass surgery: a qualitative and quantitative analysis. Heart Lung. 2003;32:23-31.

15. Fitzsimons D, Parahoo K, Stringer M. Waiting for coronary artery bypass surgery: a qualitative analysis. J Adv Nurs. 2000;32:1243-52.

16. Koivula M, Paunonen-IImonen M, Tarkka MT, Tarkka M, Laippala P. Fear and anxiety in patients awaiting coronary artery bypass grafting. Heart Lung. 2001;30:302-11.

17. Dickerson SS, Alqaissi N, Underhill M, Lally RM. Surviving the wait: defining support while awaiting breast cancer surgery. J Adv Nurs. 2011;67:1468-79.

18. Magnusson HK, Felländer-Tsai, L. Hansson, M G., Ryd, L:: Cancellations of elective surgery may cause an inferior postoperative course: the 'invisible hand' of health-care prioritization? Clin Ethics 2011, 6:27-31.

19. Dexter F, Abouleish AE, Epstein RH, Whitten CW, Lubarsky DA. Use of operating room information system data to predict the impact of reducing turnover times on staffing costs. Anesth Analg. 2003:97:1119-26.

20. Siegmueller $C$, Herden-Kirchhoff $O$. Measuring operating theatre list efficiency requires acknowledgement of costs. Anaesthesia. 2010;65:84-5. author reply 85-86

21. Koljonen V, Jero J, Vuoristo T, Niskanen M. Late cancellations in ENT surgery - reasons and costs [25]. Clin Otolaryngol. 2007;32:318-9.

22. Perroca M, Jerico Mde C, Facundin S. Surgery cancelling at a teaching hospital: implications for cost management. Rev Lat Am Enfermagem. 2007;15:1018-24.

23. Walsh U, Alfhaily F, Gupta R, Vinayagam D, Whitlow B. Theatre sending: how long does it take and what is the cost of late starts? Gynecol Surg. 2010;7:307-10. 
24. Cardoen B, Demeulemeester E, Beliën J. Operating room planning and scheduling: a literature review. Eur J Oper Res. 2010;201:921-32.

25. Dexter F, Marcon E, Epstein RH: Monitoring waiting times (mean tardiness) on the day of elective surgery. In.; 2006.

26. Rosen AC, Dexter F. Lessons from evidence-based operating room management in balancing the needs for efficient, effective and ethical healthcare. Am. J. Bioeth. 2009;9:43-4.

27. Crist BD, Ferguson T, Murtha YM, Lee MA. Surgical timing of treating injured extremities. J Bone Joint Surg Am. 2012;94:1514-24.

28. Caesar U, Karlsson J, Olsson LE, Samuelsson K, Hansson-Olofsson E. Incidence and root causes of cancellations for elective orthopaedic procedures: a single center experience of 17,625 consecutive cases. Patient Saf Surgery. 2014; 8:24.

29. Cosgrove JF, Gaughan M, Snowden CP, Lees T. Decreasing delays in urgent and expedited surgery in a university teaching hospital through audit and communication between peri-operative and surgical directorates. Anaesthesia. 2008;63:599-603.

30. Leppaniemi A, Jousela I. A traffic-light coding system to organize emergency surgery across surgical disciplines. Br J Surg. 2014;101:e134-40.

31. Lofvendahl S, Eckerlund I, Hansagi H, Malmqvist B, Resch S, Hanning M. Waiting for orthopaedic surgery: factors associated with waiting times and patients' opinion. Int J Qual Health Care. 2005;17:133-40.

32. Eldas SD, Aslan FE. The reasons for postponement of scheduled orthopedic surgical operations and its effect on the patients'anxiety and pain levels. Acta Orthop Traumatol Turc. 2004;38:212-9.

33. Waiting time in Swedish Healthcare (Väntetider i vården) [http://www.vantetider.se/].

34. Schuster M, Neumann C, Neumann K, Braun J, Geldner G, Martin J, Spies C, Bauer M, Group CS. The effect of hospital size and surgical service on case cancellation in elective surgery: results from a prospective multicenter study. Anesth Analg. 2011;113:578-85.

35. Chiu CH, Lee A, Chui PT: Cancellation of elective operations on the day of intended surgery in a Hong Kong hospital: point prevalence and reasons. Hong Kong Med. J. 2012, 18:5-10

36. Laisi J, Tohmo H, Keranen U. Surgery cancelation on the day of surgery in same-day admission in a finnish hospital. Scand. J. Surg. 2013;102:204-8.

37. Robb WB, O'Sullivan MJ, Brannigan AE, Bouchier-Hayes DJ. Are elective surgical operations cancelled due to increasing medical admissions? Ir J Med Sci. 2004;173:129-32.

38. May JH, Spangler WE, Strum DP, Vargas LG. The surgical scheduling problem: current research and future opportunities. Prod Oper Manag. 2011;20:392-405.

39. Lee A, Kerridge R, Chui P, Chiu C, Gin T. Perioperative systems as a quality model of perioperative medicine and surgical care. Health Policy. 2011;102:214-22.

40. The National Board of Health and Welfare in Sweden. Guidelines for care and treatment of hip fractures (Socialstyrelsens riktlinjer för vård och behandling av höftfraktur) Sweden. 2003.

41. Kelly-Pettersson P, Samuelsson B, Muren O, Unbeck M, Gordon M, Stark A, Sköldenberg O. Waiting time to surgery is correlated with an increased risk of serious adverse events during hospital stay in patients with hip-fracture: a cohort study. Int J Nurs Stud. 2017;69:91-7.

42. Argo JL, Vick CC, Graham LA, Itani KMF, Bishop MJ, Hawn MT. Elective surgical case cancellation in the veterans health administration system: identifying areas for improvement. Am J Surg. 2009;198:600-6.

43. Dexter F, Shi P, Epstein RH. Descriptive study of case scheduling and cancellations within 1 week of the day of surgery. Anesth Analg. 2012;115:1188-95.

44. Bhattacharyya T, Vrahas MS, Morrison SM, Kim E, Wiklund RA, Smith RM, Rubash HE. The value of the dedicated orthopaedic trauma operating room. J Trauma. 2006;60:1336-40. discussion 1340-1331

45. Lemos D, Nilssen E, Khatiwada B, Elder GM, Reindl R, Berry GK, Harvey EJ. Dedicated orthopedic trauma theatres: effect on morbidity and mortality in a single trauma centre. Can J Surg J. 2009;52:87-91.

46. Min W, Wolinsky PR. The dedicated orthopedic trauma operating room. J Trauma. 2011:71:513-5.

47. Wixted JJ, Reed M, Eskander MS, Millar B, Anderson RC, Bagchi K, Kaur S, Franklin P, Leclair W. The effect of an orthopedic trauma room on after-hours surgery at a level one trauma center. J Orthop Trauma. 2008;22:234-6.

48. Baraza N, Lever S, Dhukaram V. Home therapy pathway - safe and streamlined method of initial management of ankle fractures. Foot Ankle Surg. 2013;19:250-4.

49. Lloyd JM, Martin R, Rajagopolan S, Zieneh N, Hartley R. An innovative and cost-effective way of managing ankle fractures prior to surgery - home therapy. Ann R Coll Surg Engl. 2010;92:615-8.

50. Mclsaac DI, Abdulla K, Yang H, Sundaresan S, Doering P, Vaswani SG, Thavorn K, Forster AJ: Association of delay of urgent or emergency surgery with mortality and use of health care resources: a propensity score-matched observational cohort study.(Research). CMAJ 2017, 189:E905.

51. Cordero J, Maldonado A, Iborra S. Surgical delay as a risk factor for wound infection after a hip fracture. Injury. 2016:47:S56-60.

52. Singh RA, Trickett R, Hodgson P. Early versus late surgery for closed ankle fractures. J. Orthop. Surg. (Hong Kong). 2015;23:341-4. 